\title{
EL POZO Y ABASTO DE NIEVE DEL CABILDO DE LA CATEDRAL DE OURENSE
}

\author{
Por \\ MIGUEL ÁNGEL GONZÁLEZ GARCÍA
}

Los calores intensos del estío orensano, encontraban un cierto alivio en la refrigeración de la bebida por medio de la nieve que se recogía y apisonaba en el invierno en un pozo situado en la Cabeza de Meda. Esta solución fue muy común a lo largo del antiguo régimen, cabildos catedralicios, comunidades monásticas, casas nobiliarias y concejos se preocuparon de construir estas «neveras» y de abastecer con este producto a los individuos de sus comunidades o a las élites urbanas con mayor poder adquisitivo y por tanto más deseosas de todo tipo de refinamiento.

Se usó el hielo además de para refrescar las bebidas, para la fabricación de helados, granizados y sorbetes; para la conservación de los alimentos, carnes y pescados especialmente y para usos medicinales de finalidad antipirética.

Los pozos de la nieve tienen un indudable interés etnográfico en cuanto construcciones populares con técnicas peculiares, y una finalidad hoy ya definitivamente abandonada, así mismo no deja de interesar el conocimiento de estos usos como expresión del refinamiento de las clases pudientes del antiguo régimen e incluso dentro de la historia de la gastronomía y de la medicina es pertinente considerar el uso de la nieve y su distribución. Nosotros abordamos el tema principalmente desde la historia. La historia concreta del abasto de nieve al Cabildo de la Catedral de Orense y como un capítulo más del vivir de esta institución tan influyente en el vivir ciudadano del pasado.

"CUADERNOS DE ESTUdIOS GALLEGOS", Tomo XLVI, Fascículo 111, Santiago 1999. 
En nuestro estudio seguimos las incidencias del abasto de la nieve a los eclesiásticos de la Catedral, al margen del abasto ciudadano y señalamos los conflictos y las concordias entre el cabildo y la Ciudad por este tema.

Las actas capitulares son la fuente principal de información, motivada principalmente por el cobro de ciertas imposiciones a los consumidores que el Cabildo protesta por ir contra sus prerrogativas y por el deseo de la institución capitular de asegurar cada verano este apetecido refrigerio. La cronología de nuestro trabajo se alarga hasta los últimos años del siglo XVIII.

\section{LAS PRIMERAS NOTICIAS}

Las primeras noticias del pozo de la nieve de la Catedral de Ourense, son del siglo XVII. Concretamente en el cabildo del día 14 de junio de 1638 se dice: «Propúsose que Coutinón abia arrendado la sisa de la niebe y que abia impuesto en cada libra dos mrs más de los ocho que balia y los cobraba a los eclesiásticos sin que ubiese indulto para tal imposición, antes breve de su Sd. En contrario: resolvióse se presente el breve delante el Ordinario y se le pida dé censura contra él y mas personas eclesiásticas» ${ }^{1}$. Dos días después se insiste sobre lo mismo ${ }^{2}$. Ignoramos si el obispo D. Juán Velasco y Acevedo que regía entonces la sede auriense, fulminó las censuras que le pedían, pero ello ciertamente no tiene el mayor interés, siendolo sin embargo, para nuestro tema, las noticias que nos ofrece el acuerdo capitular: precio de la nieve, nombre del nevero de la ciudad, único para para eclesiásticos y para seglares y sobre todo subrayar que en aquellas fechas no era una novedad el consumo de nieve por los eclesiásticos orensanos. Este uso venía sin duda de bastantes años atrás y la resistencia del Cabildo a pagar la sisa de la nieve es evidente que también se había manifestado en un momento preteito que no podemos precisar pero que culminaría en la obtención del breve pontificio que se cita y que les aseguraría la exención tributaria.

\footnotetext{
' ACO. Actas Capitulares tomo XI, fol 249.

${ }^{2}$ ACO. Idem fol $249 \mathrm{v}$.
} 
Todo ello permite suponer que sea quizá en pleno siglo XVI cuando se inicia en Orense el consumo de nieve, aunque no aflore en la documentación, quizá porque la falta de conflictos no obliga a consignaciones precisas. La segunda referencia documental se retrasa hasta 1666 y luego en 1687 será la última vez que en este asunto se alegue el breve pontificio, cuya obtención evidencia que no era asunto de poca monta. El 14 de junio de 1687 el obispo Diego Ros de Medrano ordena al Cabildo nombre quienes señalen «la cotta fija de niebe que pueden gastar los señores eclesiásticos de la Iglesia y Ciudad para que se mandase al obligado la diese a más bajo precio que al estado secular por no dever el ecl contribuir en este tributo, pues de no hacerlo procedería contra los culpables conforme a lo dispuesto por el breve de S. Santidad» ${ }^{3}$.

\section{EN BUSCA INFRUCTUOSA DE UNA NEVERA PROPIA}

En agosto de 1666 en el tema de la nieve el Cabildo alienta una preocupación nueva: independizarse del nevero común de la ciudad y adquirir una nevera propia para lograr un más seguro y conveniente abasto de nieve durante el periodo estivo.

El 4 de agosto de 1666 el canónigo Don Antonio Pando Enríquez manifestó en cabildo que «tenía noticia que los Monjes de Ribas del Sil querían vernder una nevera que tenían, y ansí por la falta que cada día se experimentaba como por algún útil que se podía seguir» propuso su compra al Cabildo. La propuesta pareció bien a los capitulares y el canónigo Sr. Río se ofreció para ir a ver, como previa y conveniente medida la «dicha casa de la nieve» ${ }^{4}$. Reconocido el pozo y hallado en condiciones se escribió al abad del monasterio sobre el particular, leyéndose la respuesta abacial en el cabildo del 14 de agosto. El Dr. D. Pedro de Prado fue el transmisor de la información en la que el Abad de San Esteban, con las cortesías y etiquetas del momento, decía que se holgaba de habérsele ofrecido ocasión de servir al Cabildo con el pozo de la nieve y que vendría a Orense se mayordomo de la casa para ajustarlo. ${ }^{5}$

\footnotetext{
${ }^{3}$ Idem. Tomo XVII fol 353.

${ }^{4}$ Idem. Tomo XV, fol 170.

${ }^{5}$ ACO. Actas. Tomo XV fol 172.
} 
Sin embargo una serie de dudas se non plantean sobre la exactitud de las noticias del Sr. Prado sobre el propósito del monasterio de vender la nevera y sobre la venida del mayordomo a Orense y ello porque en el mes de noviembre de ese mismo año el canónigo «Sr. Prado da cuenta de que después de haber(se) ofrecido ir a Ribas del Sil al ajuste del pozo de la nieve le habian sobrevenido algunos achaques por lo que le resultaba imposible tal desplazamiento; así rogaba al Cabildo pusiese los ojos en otro seños que él desde luego le ofrecía su mula». En vista de ello, el Cabildo nombró al secretario Lic. D. Juan Francisco de Sesma a quien otorgó poder para el ajuste del pozo con el P. Abad y monjes de dicho convento, ante el escribano real Antonio Soutullo. ${ }^{6}$ El canónigo Sesma viajó hasta San Esteban y el 22 de diciembre informa al Cabildo del resultado de su gestión con el abad benedictino: Este «remitía al Cabildo las llaves de la nevera para que este año se llene».

El Cabildo comisionó entonces a los Señores Araujo y Blazquez para buscar quien se encargase de la recogida y abasto de la nieve o como dice exactamente el acuerdo capitular para que "estén con Canal y ajusten en la forma que esto se ha de hacer» ${ }^{7}$. Fueron eficaces en cumplir el acuerdo y el 5 de enero de 1667 «los capellanes Joseph de Canal y Rivela entraron (en Cabildo) y dijeron en como tenían adreçado el pozo de la nieve y que por este año lo llenarían y darían a los señores de el Cabildo a seis mrs. La libra de nieve y pagarían -el foro, sin duda-al Convento de Ribas del Sil».

En esa misma ocasión solicitaron «una cobachuela» de las de debajo de la iglesia, pagando por ella lo acostumbrado a la Fábrica «y $d l$ cavildo vino en ello». ${ }^{8}$ Quizá este procedimiento en el que no parece exista improvisación alguna, puede permitirnos pensar que ya con anterioridad el Cabildo se haya abastecido de nieve por cuenta propia: el «estar con Canal» y la facilidad con la que este dispone el tema del pozo, de la covachuela de la Catedral, que serviría de almacén de distribución y el ofrecimiento de pagar por ella «lo acostumbrado» avalan esta sospecha aunque las noticias documentales nos falten.

\footnotetext{
${ }^{6}$ Idem. Idem fol $183 \mathrm{v}$

${ }^{7}$ Idem. Idem fol 188.

${ }^{8}$ Idem. Idem fol. 202.
} 
En noviembre de 1668 se escribe de nuevo al P. Abad de Ribas del Sil buscando un acuerdo firme y definitivo sobre la nevera: se le cuestionaba "si es ocasión de hacer el fuero de dicho pozo ${ }^{9}$. Tampoco ahora se consigue nada en firme, y otra carta cortés pone dilación a los deseos del Cabildo. El 7 de diciembre de diciembre se leyó la respuesta abacial: «leyóse una carta del Padre Abad de Ribas del Sil respuesta de la del Cavildo en la que dice queda mortificado de no poder servir al Cavildo como quisiera pero que su general no le havía querido dar licencia para que se hiciese el fuero al Cavildo, que si quería lo haría a un particular y que seguramente se podía mandar llenar el pozo este año» ${ }^{10}$. El Cabildo no deseaba prolongar estas soluciones transitorias y busca abordar definitivamente el problema disponiendo a su gusto de un pozo propio para la recogida de la nieve. Se piensa, en la compra. En septiembre de 1673 el Deán Lic. D. Gonzalo de Armada y Araujo, propuso en Cabildo que «tenía entendido que el Convento de Rivas del Sil quería bender un pozo de niebe, que sería conveniente que el Cavildo lo comprase»". Se encargó de nuevo al Sr. Río del asunto pero tampoco esta vez la gestión fue exitosa.

Se intenta otra solución: edificación de un pozo propio. Se piensa en la cumbre de San Mamed. La propuesta se propone en el cabildo de 10 de septiembre de 1688: "propuso el Sr. Castell avia ydo de orden del Cavildo al zerro de San Mamed a ver si avía sitio competente donde hacer pozo de niebe $p^{a}$ el abasto eclessco. y ynformado el Cavdo. De averle acordó q. hiziese dicho Sr. Castell las dilixas conzernientes a ello y para ello se le dio poder» ${ }^{12}$. Tampoco esta tentativa culminó con éxito sin que conozcamos las causas. El Cabildo tras tantos intentos infructuosos parece resignarse a vivir de prestado. Desde 1690, al menos el Cabildo utilizará un pozo del monasterio de Xunqueira de Espadañedo por el que anualmente pagará el foro correspondiente. ${ }^{13}$

Sobre este pozo daremos a conocer algunos pormenores.

\footnotetext{
${ }^{9}$ Idem. Tomo XVI, fol $35 \mathrm{v}$.

${ }^{10}$ Idem. Idem. Fol $36 \mathrm{v}$.

${ }^{11}$ Idem. Idem. Fol 251 v. Cabildo de 7 de septiembre.

${ }^{12}$ Idem. Tomo XVII. Fol 428.

${ }^{13}$ En 1675 documentalmente sabemos que se sigue pidiendo el pozo al Monasterio de Ribas do Sil.
}

"CUADERNOS DE ESTUdiOS GALLEGOS", Tomo XLVI, Fascículo 111, Santiago 1999. 


\section{DETALLES SOBRE EL POZO DE LA NIEVE}

La documentación incuestionablemente certifica que desde el año 1667 el Cabildo dispone de un pozo de la nieve, en empréstito o en foro, y el abasto de la nieve se hace durante los veranos con regularidad, y en numerosas ocasiones se habla de la pertenencia del pozo al Cabildo. El Cabildo, lo restaura, lo revisa cada año antes de escriturar el arrendamiento, le llama «suyo» en las escrituras públicas y hasta sostiene por su causa algún pleito en los tribunales de la Real Audiencia de Galicia.

Sin embargo es también cierto que el Cabildo no era propietario. Los diversos intentos de compra y edificación no tuvieron éxito. El que utiliza lo tiene en foro del monasterio de Xunqueira de Espadañedo desde el año 1691, pagando anualmente 60 reales de vellón ${ }^{14}$.

Este pozo que llamaremos del Cabildo, estaba situado en la cumbre de la sierra de Cabeza de Meda, a «cautro leguas» de camino de la ciudad. No lejos estaba también el pozo de la ciudad, que al parecer ni era tan amplio, ni estaba tan atendido y cuidado como el del Cabildo, además también allí estaban algunos otros de monasterios y acaso de particulares y desde luego el del monasterio de Xunqueira de Espadañedo, distinto del aforado al Cabildo ${ }^{15}$.

Estaba colocado el pozo en el interior de una caseta baja con techumbre de madera en un principio y con dos puertas, la principal con llave y otra lateral o traviesa

cerrada con terrones y que «solo se abría para recoger la nieve». Contiguos a la caseta del pozo estaban una cuadra y otra casita o alpendre «para recogerse la gente». Todo ello cubierto de teja y circundado de un muro alto «para que no suban las cabras» y rompiesen las tejas.

Cada año a finales del verano e incluso ya entrado el otoño solía ir un canónigo o racionero, natural o conocedor del país, a reconocer el pozo, juntamente con el carpintero de la Iglesia para comprobar de que el pozo estaba en condiciones para la eficaz recogida de la nieve. Sin este requi-

${ }^{14}$ En el cabildo de 5 de octubre de 1694 se acuerda que el «mayordomo de la mesa capitular» libre a favor del Convento de Junquera $60 \mathrm{rls}$ del pozo de la nieve. Actas Capitulares 1689-1699 fol 273 v.

${ }^{15}$ Según se verá lo utilizará el Cabildo en 1734 , mientras arreglaba el «suyo». 
sito no se procedía a la renovación del arrendamiento siendo esta la primera condición exigida por los neveros. Así en 1722 se acuerda en Cabildo que el canónigo D. Francisco Alvarez «se valga de su paisano el Abad de Edrada $p^{a} q$. reconozca el pozo, le haga componer y aún recoger la nieve». ${ }^{16}$ Otras veces, como en 1743, es el canónigo Sr. Paramos tenenciero de los Abeledos. ${ }^{17}$ Otras el racionero García «práctico en aquel país».

Casi siempre el pozo necesitaba algún reparo y con frecuencia de relativa importancia. Los vendavales y otras inclemencias atmósféricas en aquellas alturas, los niños y pastores y las cabras solían romper a lo largo del año muchas tejas, luego el agua pudría las maderas y derribaba los muros. Las reparaciones solían ser costosas y difíciles, en especial el acarreo de los materiales hasta aquellos altos y escarpados parajes. La primera reparación de la que tenemos constancia documental es de 1689, la hace el canónigo Castel a cuenta de la obra pía del Obispo Castañón. ${ }^{18}$

El año 1734 como la techumbre amenazase ruina, «para evitar repetidos gastos» se penso en hacerle una bóveda de piedra, que se ajustó con el carpintero Antonio de Castro en 1.750 reales. Corrió con la administración el canónigo Cárdenas como veremos; no se pudo trabajar en aquel invierno con el temporal, pero en octubre de 1735 estaba ya terminada aunque los gastos se habían doblado, abonándosele a Castro los 3.000 reales de coste. Mientras tanto el Cabildo utilizó «el [pozo] de los monjes de Junquera que lo tenían desocupado» ${ }^{19}$.

Algunos inviernos solía escasear la caida de la nieve en la Sierra de Cabeza de Meda, o al menos no cuajaba o duraba el tiempo necesario para recogerla. Entonces era necesario acudir a la sierra de San Mamed donde jamás solía faltar en sobrada cantidad. Entonces se recogía allí previamente en barracas y desde allí se trasladaba en tiempo oportuno al pozo, pero como es natural este proceso encarecía el producto. De algunos años, por ejemplo, sabemos que el Cabildo solicitó y obtuvo en alquiler del monasterio de Montederramo las barracas de San Mamed con el pozo correspondiente.

\footnotetext{
${ }^{16}$ Actas Capitulares 1713-1722. Cabildo de 21 de enero de 1722.

${ }^{17}$ Idem 1734-1743. Cabildo de 14 de enero de 1743.

${ }^{18}$ Actas. Cabildo de 7 de diciembre de 1689. Fol 353.

${ }^{19}$ Actas (1734-1743) cabildo de 13 de noviembre de 1734; idem de 14 de octubre de 1734 y de 20 de octubre de 1735 .
}

"CUADERNOS DE ESTUDIOS GALLEGOS", Tomo XLVI, Fascículo 111, Santiago 1999. 
Pero lo habitual era que la nieve se recogiese en Cabeza de Meda, mediante obreros naturales de aquel contorno empleados a jornal. Se recogía y llenaba el pozo «por la puerta traviesa»; se pisaba hasta endurecerla lo posible y se protegía después convenientemente con sal, paja y tierra. Llegado el verano se abría el pozo de noche para poner la nieve en las cargas; y a la luz de un candil de aceite, con una hoz pesada - de seis libras- hecha a propósito, el cortador, iba partiendo trozos de aquella cantera de de nieve endurecida que envuelta en paja y sal era trasportada de noche hasta el depósito o abacería de la Capital. ${ }^{20}$

\section{ADMINISTRACCIÓN DIRECTA DEL CABILDO}

Una nueva forma, además del arriendo a los neveros, de procurarse el abasto de nieve durante el verano, solía ser la administración directa por parte del Cabildo. Era ciertamente un recurso extraordinario al que solo en contadas ocasiones se recurre para que por nada faltase en los calores rigurosos del estío auriense un sorbo helado.

Multiples causas llevaban al Cabildo a tomar esta medida. Cada año, llegado el tiempo a propósito, generalmente en diciembre, se fijaban cédulas ofreciendo el arriendo del pozo y abasto de nieve al mejor postor. Pero a veces faltaban los postores. Las razones la poca rentabilidad del oficio ya que fuera de años muy calurosos, que abundaban, era escaso el consumo de nieve como lo expresa con preocupación en 1693 el racionero Mira con estas palabras: «...el consumo de la nieve es tan corto que no produce para el coste de portes y vendaje». No dejaba al fin y al cabo de considerarse un artículo de lujo y por tanto al alcance de los «señores», nobleza y eclesiásticos únicos que poseían y manejaban dinero y podían gastarlo en ese tipo de refinamientos, hoy felizmente al alcance de cualquiera, es decir que el mercado era reducido y además existían dos abacerías en la ciudad, la del cabildo y la de la ciudad y esto hacía que ambos neveros tuviesen al fin de temparadas pocas ganancias. En virtud de ello funda José Rodríguez Placer, nevero de la ciudad, un extraño memorial que presenta al Cabildo en mayo de 1672, obedeciendo a esta com-

${ }^{20}$ ACO. Papeles de la nieve.

"CUADERNOS DE ESTUDIOS GALLEGOS", Tomo XLVI, Fascículo 111, Santiago 1999. 
petencia la inquina que Placer manifiesta al nevero del Cabildo. Si a ello añadimos los 60 rls de pensión del foro del pozo y los 20 ducados libres cada año al Cabildo, más los gastos de recolección y transporte nada extraño es que muchas veces no hubiese personas interesadas en el abasto de la nieve, que echando cuentas no resultaba un negocio demasiado feliz.

Además a esto se añadía la exclusión que el propio Cabildo hacía de los neveros cuyo servicio había sido deficiente. En octubre de 1722 se mandan poner cédulas... «pero no se admita al que la tuvo hasta aquí». Era este nevero, Juan Fernández a quien se le había cedido en enero de 1721 y de nuevo la solicitaba en enero del año siguiente (1722). Hubo vez en que se hizo necesario proceder por la vía judicial contra algún nevero, como sucedió en 1749 con Pedro Cachalvite, y quitarle la nieve, no «por motivo de algunas faltas», como reconoce el mismo, sino de «infinitas faltas», en frase del Cabildo ${ }^{21}$. No se portó mejor su sucesor inmediato, Ambrosio Casnova contra quien se acordó «tomar providencias... por las faltas que hizo... procurando que otro año no suceda lo que este» ${ }^{22}$.

Este descontento lo manifestará el Cabildo de otros obligados, de uno en 1689 «porque había subido el precio de ella a dos cuartos, doblándole», de otro por haber ido "contra lo capitulado en la escriptura», en 1735 , o porque «de la poca(nieve) que tenía recogida la divertía fuera de la ciudad» en 1690 . O por «continuas faltas... dejando de dar surtimiento en días de mucho calor» etc. etc.

Todo ello hace que el Cabildo, aleccionado fijase a su favor con mucho cuidado las condiciones de la escritura, exigiese fianzas abonadas sin olvidar las claúsulas habituales en los contratos en las que quien aceptaba la responsabilidad se «obligaba con su persona y bienes muebles y raíces habidos y por haber» a cumplir con las condiciones estipuladas, aceptando que a ello sería apremiado por todo rigor de derecho y pagar las costas y daños que por su omisión se causaren, dando poder y sometiéndose a las justicias de su fuero y jurisdicción competentes en especial a las que de la causa puedan y deban conocer para que le hagan cumplir lo contenido como si fuese sentencia definitiva de juez competente pasada en auto-

\footnotetext{
${ }^{21}$ Actas Capitulares de 7 y 30 de julio de 1749 .

${ }^{22}$ IDEM. Cabildo de 17 y 19 de septiembre de 1750.
} 
ridad de cosa juzgada cerca de la cual renunciaba todas las leyes de su favor y las generales. Terminología grandilocuente, con frecuencia letra muerta y que llevaba de querer exigirse a pleitos casi siempre largos.

En los momentos en los que no se encuentra nevero profesional el Cabildo se encarga por si mismo del problema de la nieve. La primera medida era nombrar comisionados que tomasen las providencias necesarias. Solían ser estos uno o más canónigos, quienes por la experiencia de años anteriores o por ser naturales de las cercanías de la Cabeza de Meda tenían más conocimiento y recursos que otros poco expertos en ese tema. El canónigo comisionado si no atendía personalmente a la administración se entendía con algún racionero o capellán de coro.

En otras ocasiones en los memoriales presentados figuraban condiciones inadmisibles para el Cabildo, como ocurrió con José Pato, vecino de Xunqueira de Espadañedo en diciembre de 1728, con José R. Placer, nevero de la ciudad, que solo ofrecía 10 ducados libres, la mitad de lo que entonces se solía; y con Manuel Armada, mercader en 1733 que reclamaba «ser de los exentos del Cabildo para todos los cargos concejiles», y lo que es peor «que no cayendo nieve en el término de dicho pozo, no pudiera obligársele al abasto, ni por ningún pretexto a recogerla en otra parte». La primera exigencia no creaba dificultad especial y se lo hubiese concedido el Cabildo, como después lo hará a otros, pero en lo segundo no. Si no caía nieve en Cabeza de Meda, que no era infrecuente, el Cabildo abonaría la diferencia de gasto para recogerla, pagaría más cara la libra, adelantaría el dinero; pero ante todo, y precisamente para asegurar «que no falte nieve», exigiría de todos los postores, como lo exigió a Marcos Alavarez en 1722 «que la obligación sea general, caiga o nocaiga en el término (del pozo)».

A Juan Nicolás de Espinosa, nevero de la ciudad, que solicitaba se le encomendase la nieve del Cabildo en las mismas condiciones que el Lcdo. Butrón, a seis mrs. la libra, se le niega porque el Cabildo «vió inconveniente insuperable el que la nieve de la ciudad estaba puesta a dis qtos la libra y habiendo de correr por un mismo nevero era muy perjudicial la separación de precios». Allanado este obstáculo y poniéndola al mismo precio de $6 \mathrm{mrs}$ para «eclesiásticos y seglares» por todo el año (1691) se le concede. 


\section{NOTICIAS E INCIDENCIAS DEL ABASTO DE NIEVE}

Siguiendo un orden cronológico, veremos las noticias y referencias que las actas capitulares y otra documentación catedralicia nos ofrece del asunto de la nieve.

En 1691 el Licenciado Butron, capellán de coro, «obligado de la nieve del Cabildo, pide se le permita venderla en el bajo del cuarto nuevo que sirve de taller», y se le concedió. La vendía, como queda dicho a $6 \mathrm{mrs}$. la libra.

En 1693 el Sr. Cid, capitular encargado de buscar nevero dice «que no hay postor». Un mes más tarde el mismo señor da cuenta de que el Racionero Mira le escribe cómo de orden del Cabildo está asistiendo a recoger la 1 nieve, pero que se halla achacoso y con calentura, imposibilitado de asistir. Entonces se acuerda que vaya a suplirle el Lcdo. Rosendo, capellán de coro y "que reconociendo se hace (la recogida) con conveniencia, se recoja la nieve que se pudiese y siendo el coste considerable se recoja hasta igualar con la puerta del pozo y no más»; es decir, según se concretó al día siguiente: «se recojan hasta 400 cargas con que parece se podrá conservar», ya que basta para su consumo. En junio de aquel año 1693 encontramos ya restablecido, al frente de la abacería del Cabildo, quejándose, según hemos anotado, del escaso consumo de la nieve y de que encima "algunas criadas de eclesiásticos llevan la nieve de la nevera de la ciudad, y que otras toman abasto en la carnicería del Cabildo siendo para seglares». No obstante la propuesta de Mira acordó el Cabildo, y esto a fines de septiembre, que «se traiga la nieve».

En 1716 se acuerda que «el Lic. Rey pase a recoger la nieve y el Señor Espinosa le de el dinero para los gastos». Se pusieron cédulas, pero en vano. Como apretaba el calor se acordó que «venga nieve para la Semana Santa y que lo disponga el Sr. Cornejo y que se venda a 6 mrs. mientras no la trajere el nevero de la ciudad y después a 4». La vendía un tal Tabara. El primero de julio D. Francisco del Villar, canónigo «propuso que entraría él en la administración de la nieve desde el día 2 y daría al Cabildo mil reales mas todo el producto habido hasta hoy si el pozo tenía 200 cargas». Lo reconoció enseguida, vio que las tenía y se le confirmó el contrato. Pero pronto se cansó. El 31 del mismo mes ya propuso en Cabildo que «quería ceder la nieve al nevero de la ciudad y habiéndose tratado largamente este punto, se salió el Sr. Alvarez a asistir al Obispo 
en la fiesta de San Ignacio y por no quedar número -no obstante ser 10 los asistentes- se suspendió el Cabildo».

En 1723 aunque había nevero vemos al Cabildo actuando por su cuenta. En el Cabildo de 22 de marzo «llevose un memorial del arrendatario de la nieve que dice que aunque concurrió a cogerla dos veces y cayó, permaneció tan poco tiempo que no cogió casi nada y así pide se informe de esto y en caso de no caer más le proteja el Caboldo para las barracas de San Mamed; y se acordó atento considera el Cabildo ser sujeto incapaz de cumplir se tome providencia para que no haya falta de nieve, ya sea recogiéndose, ya sea estando con los abades de los monasterios que la tienen por si pueden venderla y que solo se traiga en este caso la que fuese necesaria para el consumo de los individuos de la Iglesia... que los Srs. Deán, Zeballos, Piornedo y Cid sin venir a Cabildo den las providencias conducentes». Al fin debió recogerla el mismo nevero, que era posiblemente José Placer acaso en la sierra de San Mamed, pues en el Cabildo de 19 de junio se leyó un memorial del nevero representando el mucho coste que tuvo el recoger la nieve y pide se le de licencia, no obstante deber por la escritura dar la nieve a $6 \mathrm{mrs}$., para poder darla a dos cuartos.

En 1729 nos encontramos, aunque no por primera vez, con el racionero Sr. García. En agosto de 1723 había estado con el carpintero de la Catedral reconociendo el pozo de la nieve para repararlo en lo necesario. Ahora, en diciembre de 1729, se documenta que de nuevo se responsabilizó del reparo: "respecto corrió con la composición del pozo», se le manda «pase a reconocerle e informe de su estado». Pero todavía es mayor su responsabilidad en este negocio; el Sr. Pardiñas da cuenta «que el que corrió con la niebe del año pasado no quería continuar», entonces el Cabildo temeroso de no encontrar quien acepte el arriendo, por lo adelantado de la estación encarga al Sr. García "prevenga persona que se disponga para recoger la nieve y llenar el pozo cuando sea el tiempo oportuno».

Así se efectúa. El acta con lo acordado tiene interés la conozcamos por su importancia posterior. Es el cabildo de 9 de enero de 1730. «Propuso el Sr. Pardiñas como José Placer, nevero, no quiere entrar en el pozo de la niebe en los veinte ducados, sino dando diez y además que se le ha de dar un oficio de essempción a su arvitrio y habiéndose tratado sobre ello, habiendo dicho el Sr. Zevallos estaba debiendo de los años 
pasados sesenta ducados los que no podía cobrar se acordó que inmediatamente se le encause por ellos y en que a la nieve se llame al Sr. Racionero García como práctico en aquel país por si gusta buscar persona que corra con el abasto de nieve llenando el pozo que para ello se le dará por el Sr. Zevallos los medios necesarios, y habiendo entrado dicho Sr. García enterado de la proposición puso la dificultad en hallar paja y conducirla y el Sr.Muñoz dijo haría diligencia por la paja y por conducirla y en vista de esto el Sr. García dijo tenía persona de satisfacción y poniéndole la paja arriba correrá con recoger la nieve y en todo se conformó el Cabldo» ${ }^{23}$

En la primera decena de marzo tenemos en la cumbre de Cabeza de Meda al Sr. García. Había nevado copiosamente, pero no podía recoger un solo copo de nieve por las razones que explica al Deán en una carta leída en el Cabildo del día 11 de marzo. "...aunque hay nieve bastante no halla gente para recogerla respecto el nevero de la ciudad la tiene ocupada y aunque ofreció más salario no pudo conseguirlos atento a que la obliga la justicia para la ciudad, y que el Cabildo tome la providencia que le pareciere pues él no puede detenerse más en aquel paraxe». El cabildo no pareció darle importancia al incidente: así lo refleja el laconismo frío del acta de aquella misma fecha: «se acordó que la nieve se recoja como está determinado».

Otra segunda carta del Sr. García da cuenta "que el nevero de la ciudad quiere entrar en el arriendo del pozo del Cabildo por tres años, dando por cada uno 20 ducados dándole por los dos últimos essempción».

Todo cuando llevamos escrito del nevero José Placer se adivina como se iba caldeando el ambiente para el incendio del pleito de la nieve con la ciudad. Sólo faltaba el chispazo, que no tardaría sino unos meses en producirse. Se evidencia en todo ello la mala voluntad del nevero de la ciudad, estuviese o no respaldado por las autoridades municipales. Así al menos lo entendió el canónigo Pereira que en el Cabildo de 15 de abril le puso el veto y «contradijo el que se le diese al nevero de la ciudad»; era en principio una prevención que sin embargo los hechos confirmarán. Todo aquel año de 1730, año de diferencias con la ciudad, ¿corrió con la nieve el racionero García?, o ¿se la dieron a Gregorio Fernández, vecino

${ }^{23}$ ACO. Actas capitulares 1730.

"CUADERNOS DE ESTUDIOS GALLEGOS", Tomo XLVI, Fascículo 111, Santiago 1999. 
de Ourense, que la pidió a mediados de junio? No lo sabemos. Lo que si es bien conocido es que al menos el año 1731 estuvo a su cargo y lo hizo con tanto acierto y sacrificio que arrancó un voto de gracias al Cabildo, siempre tan parco en los elogios. El 12 de diciembre de 1731, después de rechazar un memorial de José Pato «se acordó respecto no estar el Sr. García en la Iglesia, [el Sr. Deán] le dé las gracias en nombre del Cabildo por lo bien que ha dirigido la deshecha de la nieve el año pasado y al mismo tiempo le diga en nombre del Cabildo espera deberle que continúe en este año a dar la providencias conducentes para recoger la nieve y para la deshecha de ella». ${ }^{24}$

Pero como no es infrecuente en el vivir las alabanzas vienen a veces cogidas de la mano, jugando a la rueda rueda, con los vituperios, poco más de medio año después, en agosto de 1732, se advirtió la falta de la nieve. Pasan dos capitulares a reconocer el pozo, encuentran muy poca y en malas condiciones, la llave en poder del nevero de la ciudad; se informan y creen haberse asegurado de la mala conducta en la recogida de la nieve - «hecha solo 3 días y por mujeres». Se llama a Cabildo al Sr. García para hacerle cargo de todo lo ocurrido; no satifacen los descargos presentados y «se acordó que no se le abonen al Sr. García los gastos hechos», pasando la llave del pozo al Sr. Medela encargado de providenciar sobre la nieve el año que viene.

Pronto se aclararon las cosas y se le hizo justicia al racionero. En enero de 1733 atenuadas algunas condiciones se le remató la nieve a Armada, por tres años, pero no debió llevarse a cabo. En mayo el Cabildo vacila varias veces entre aceptar o no aceptar un memorial de José R. Placer. Volvió sin duda a faltar la nieve. El 11 de julio hallamos ya otra vez al Sr. García reconociendo el pozo, lo halló muy deteriorado y a su parecer solo habrá 100 cargas de ella y que si se detienen en despacharla teme se consuma toda. Se acordó que los Srs Rueda, Medela y García «pasen a reconocer el pozo y la nieve que hay y providencien no falte nieve aunque sea reparándola con sal, e informen».

El informe se dio a conocer en el cabildo de 19 de julio. Estaba concebido en estos términos: "Hallaron (la nieve) de tal mala calidad lo que atribuyen a haverse beneficiado mal al tiempo de recogerse y sólo habrá

${ }^{24}$ ACO. Actas Capitulares. 12.12.1731.

"CUADERNOS DE ESTUDIOS GALLEGOS", Tomo XLVI, Fascículo 111, Santiago 1999. 
30 cargas y así mismo reconocieron el de la Ziudad por informarse si habrá nieve en este año, y que les parece llegará a tener para dos meses y que hicieron juicio que el Sr. García tuvo muchas razones para confiar en el cortador, pero este le ha engañado pues la de la ziudad está muy trabajada y la del Cabildo muy floja y mal dispuesta... y siendo de tan mala cantidad no se podrá conducir».

De este modo queda acalarada públicamente la actuación del Sr. García de quien ninguna otra noticia tendremos en este tema de la nieve.

Aquel año se surtirán del pozo de la Ciudad, mientras no les llegaba a los capitulares del monasterio de Montederramo, al que consta trataron de escribir, pidiéndole alguna. Mientras tanto el Sr. Medela quedaba encargado de prevenir con tiempo la paja necesaria para el tiempo de recoger la nieve, y llegado este, «se escribiría a los PadresAbades de las casas inmediatas al pozo les hagan concurran sus vasallos a recoger la nieve pagándoles por lo que sea justo».

Otro personaje al que las Actas nos documentan en el año 1734 y siguientes ocupado en el asunto de la nieve, aunque no como administrador directo, es el canónigo Sr. Cárdenas. En enero el Sr. Amoeiro pone cédulas: se presenta solo Manuel de Armada; no se aceptan sus condiciones y entonces se acuerda «que el Señor Cárdenas diligencie si por aquellas cercanías hay persona que quiera encargarse de recoger la nieve». Le pidieron «1.200 reales por llenar el pozo y pareciendole mucho pasó ajustarla con un hombre abonado». No sabemos el nombre, pero si que el ajuste se hizo por aquel año, y días depués por cuatro años, y "que el Cabildo se dió por satisfecho de la buena conducta del Sr. Cárdenas». Tan satisfecho que se le dieron planos poderes para el arreglo de la techumbre del pozo completamente arruinada, «dejando a su arbitrio bóveda o madera» y que al fin se hizo de bóveda ajustándola con Antonio de Castro, carpintero, en 1.750 rls.

El 22 de octubre, Castro dice que no se puede trabajar con el temporal en aquel paraje. El invierno está encima y todavía falta mucho para terminar el arreglo del pozo y existe la posibilidad de que los de la Catedral se queden el próximo estío sin nieve. Se hará lo posible para que ello no suceda y se acuerda «se haga la obra cuanto antes ya sea obligando a Castro, ya sea dándola a otro maestro». Cárdenas irá hasta el lugar llevando otros oficiales, que tampoco pudieron resistir el temporal, buscando el diligente canónigo la siguiente solución: pedir prestado el pozo que 
usan habitualmente los monjes de Xunqueira de Espadañedo: «se le podía pedir para este año recoger el arrendatario la nieve... y componer el pozo en buen tiempo». El cabildo aprobó esta solución el el acanónigo Cárdenas volvía camino de Junquera a verse con el abad y pedirle el pozo y ajustarlo para la temporada venidera. Todavía entenderá en asuntos de la nieve el Señor Cárdenas, así en 1735, aparece multando en 5 reales al arrendatario porque se había «experimentado falta en el abasto». Acudió al corregidor para que ejecutase la multa, pero se «entrometió el rexidor Coronel Don Antono Guntín oponiéndose y diciendo palabras muy disonantes al Cabildo y al Correxidor», por lo que fue menester siguiendo el Consejo del mismo corregidor y el acuerdo del Cabildo «pedirlo judicialmente» y aún «quejarse del agravio» de Guntín.

En el mes de octubre de este año 1735 Cárdenas da cuenta de que el pozo está concluido y a Antonio de Castro se le abonan 3.000 reales, el doble de lo ajustado.

En la primavera de 1737, se encuentra el Cabildo con que «no se había recogido nieve». Y acuden a Cárdenas que cogiendo al obligado de la nieve, que sería de la parte de Xunqueira, acudió al Corregidor para que le arrestase y así lo hizo, por la grave negligencia teniendo ofrecido información y prevenidos testigos para llevar a buen fin la denuncia, que no sabemos en que terminó, oues en realidad los que al cabildo le preocupaba era procurarse nieve para el verano ya no lejano, pues era el mes de abril. Cárdenas propone de nuevo una solución eficaz: «tenía noticia había un cura en el obispado que tenía pozo de nieve lleno y aunque tenía justadas 300 cargas... llevaba muchas más». Se envió un capellán con cartas, siendo las gestiones favorables. El 15 de junio el Abad de Couso, dueño del pozo ofrece dar abasto de nieve al Cabildo y este dispuesto a no poner abacería por cuenta propia, sin daber las razones de esta determinación.

Y aquí termina la figura eficaz y diligente del Sr. Cárdenas como responsable principal en el tema de la nieve del Cabildo. Otras veces aparecerá, pero con responsabilidades más secundarias. De otros muchos señores encargados de contratar a los neveros, del visitar, el pozo etc. que sería prolijo pormenorizar es prototipo este canónigo del XVIII.

En las actas capitulares de años sucesivos afloran nuevas noticias sobre la nieve. Así en el Cabildo de 17 de abril de 1747 se vuelve a presentar el problema de la falta de nieve y se acuerda escribir al Abad de 
Montederramo para que permita en una de las barracas del monasterio que tiene en el Monte de San Mamed se recoja la nieve que necesita el Cabildo, respecto que no ha caido en la cabeza de Meda en donde tiene el Cabildo su pozo.

Este mismo año el 5 de julio el Cabildo consigna el incumplimiento por parte del obligado de la neve que ha «dexado de dar surtimiento en muchos días de riguroso calor», acordándose que el Chantre retenga el importa de la nieve que gastó en la función del Rosario y está debiendo al obligado para los efecto que halla lugar, y se dan las ordenes para proceder judicialmente contra el mal servidor. Esta noticia nos alarga el uso de la nieve en los refrigerios tan comunes en las fiestas de iglesia, en las que se convidaba al predicador y asistentes principales generalmente con agua de limón y pastas.

En 1750 el cabildo se reunirá, convocado urgentemente, el mismo día de Santiago, 25 de julio, por un asunto preocupante dice así el acta: «El Sr Deán dixo había juzgado llamar a Cabildo no obstante lasolemnidad del día para exponer que tenñia noticia habian venido de la Coruña seis o siete soldados con orden de asistir en las barracas de la nieve para no dexar venir ninguna carga para esta ciudad y hacer conducir la que hay a la Coruña; cuyo atentado es digno de consideración por el riesgo que amenaza a este lugar de faltar una provisión tan necesaria; además de ser contra la inmunidad y atención debida al Cabildo. Tratóse de esta novedad tan extraña y se acordó pase el capellán Don Manuel Cid a la nevera, se informe de lo que hay en este particular y con lo que traiga sabido se tomará la providencia que corresponde. Y a dicho capellán se le abonen los gastos que haga en este viaje».

Las noticias se alargan hasta entrado el siglo XIX aunque con menor intensidad, lo que prueba sin embargo que se seguía utilizando este medio para el refrigerio veraniego y como medicina, hasta que, con la electricidad, otros sistemas de refrigeración lo hicieron definitivamente obsoleto. 


\section{APÉNDICE}

\section{ARCHIVO DE LA CATEDRAL DE OURENSE \\ DOCUMENTOS RELACIONADOS CON EL POZO Y ABASTO \\ DE LA NIEVE AL CABILDO DE LA CATEDRAL}

172305 24, Melón.

Carta de Fray Antonio de San Pedro, monje de Melón al Cabildo sobre la Nieve.

ACO 64/78

175007 21, Ourense

Copia de un acuerdo capitular sobre el abasto de nieve.

ACO 64/02

176211 09, Santiago de Compostela.

Carta de Francisco Javier García Seron, a D. Juan Antonio Cabiedes sobre los derechos del real erario en el consumo de nieve.

ACO 64/89

176212 01, Santiago de Compostela.

Carta de Francisco Javier García Seron, al Dean y Cabildo de Ourense sobre los derechos del real erario en el consumo de nieve.

ACO 64/91

17630122 , Santiago de Compostela.

Carta de Francisco Javier García Seron, al cabildo de Ourense aprobando para el año 1763 en 130 rls de vellón los derechos del consumo de nieve. ACO 64/45

176301 08, Santiago de Compostela.

Carta de Francisco Javier García Seron, a D. Juan Antonio Cabiedes sobre los derechos del real erario en el consumo de nieve por el cabildo de Ourense.

ACO 64/90

"CUADERNOS DE ESTUdIOS GALLEGOS", Tomo XLVI, Fascículo 111, Santiago 1999. 
176402 11, Santiago de Compostela

Carta de Francisco Javier García Seron, al cabildo de Ourense señalando para el año 1764 en 130 rls de vellón los derechos del consumo de nieve. ACO 64/40

\section{26, Ourense}

Recibo de 130 rls de vellón de los derechos del consumo de nieve del Cabildo de Ourense del año 1764.

ACO 64/49

176411 13, Santiago de Compostela

Carta de Francisco Javier García Seron, al cabildo de Ourense señalando para el año 1765 en 130 rls de vellón los derechos del consumo de nieve. ACO 64/44

176501 12, Ourense

Recibo de 130 rls de vellón de los derechos del consumo de nieve del Cabildo de Ourense del año 1765

ACO 64/47

176603 22, Ourense

Recibo de 130 rls de vellón de los derechos del consumo de nieve del Cabildo de Ourense del año 1766.

ACO 64/48

176612 20, Santiago de Compostela

Carta de Francisco Javier García Seron, al cabildo de Ourense señalando para el año 1766 en 130 rls de vellón los derechos del consumo de nieve. ACO 64/41

17670129 , Ourense

Recibo de 130 rls de vellón de los derechos del consumo de nieve del Cabildo de Ourense del año 1767.

ACO 64/46

"CUADERNOS DE ESTUDIOS GALLEGOS", Tomo XLVI, Fascículo 111, Santiago 1999 
176802 03, Ourense

Recibo de 130 rls de vellón de los derechos del consumo de nieve del Cabildo de Ourense del año 1768

ACO 64/59

1769, Ourense

Lista de los Canónigos y racioneros que gastaron nieve el año 1769.

ACO 64/11

176902 22, Ourense

Recibo de José Valdivia, sargento del Regimiento de Milicias, de 900 rls por el abasto de la nieve del año 1769, al Cabildo de Ourense.

ACO 64/31

176905 18, Ourense

Recibo de 130 rls de vellón de los derechos del consumo de nieve del Cabildo de Ourense del año 1769.

ACO 64/10

176905 11, Ourense

Contrato del abasto de la nieve al cabildo de Ourense con Francisco de Novoa, vecino de Ourense para el año 1769

ACO 64/67

176910 23, Ourense

Recibo de José Valdivia de 474 rls, a cuenta por el abasto de la nieve del año 1769, al Cabildo de Ourense.

ACO 64/28

176910 24, Ourense

Contrato y obligación del abasto de la nieve al cabildo de Ourense con José Valdivia, sargento del Regimiento de Milicias, vecino de Ourense para el año 1771

ACO 64/70

"CUADERNOS DE ESTUDIOS GALLEGOS", Tomo XLVI, Fascículo 111, Santiago 1999. 
176912 31, Ourense

Recibo de José Valdivia de 1000 rls, a cuenta por el abasto de la nieve del año 1770, al Cabildo de Ourense.

ACO 64/35

1770, Ourense

Recibo de José Valdivia de 1477 rls por el retejo y puerta del pozo de la nieve y abasto de la misma.

ACO 64/33

177003 16, Ourense

Recibo de 130 rls de vellón de los derechos del consumo de nieve del Cabildo de Ourense del año 1770.

ACO 64/50

177010 12, Ourense

Contrato y obligación del abasto de la nieve al cabildo de Ourense con José Valdivia, sargento del Regimiento de Milicias, vecino de Ourense para el año 1771

ACO 64/68

177011 05, Ourense

Recibo de José Valdivia de 477 rls a cuenta, por el abasto de la nieve del año 1770, al Cabildo de Ourense.

ACO 64/27

177012 22, Ourense

Recibo de José Valdivia de 66 rls por la teja y arreglo del pozo de la nieve.

ACO 64/32

1771, Ourense

Lista de los Canónigos y racioneros que han de recibir nieve el año 1771. ACO 64/17 
177104 23, Ourense

Recibo de 130 rls de vellón de los derechos del consumo de nieve del Cabildo de Ourense del año 1771

ACO 64/51

17711209 , Ourense

Recibo de José Valdivia de 1530 rls por el abasto de la nieve del año 1770, al Cabildo de Ourense.

ACO 64/26

1772, Ourense

Lista de los Canónigos y racioneros que han de recibir nieve el año 1772.

ACO 64/18

17720109 , Ourense

Recibo de 130 rls de vellón de los derechos del consumo de nieve del Cabildo de Ourense del año 1772.

ACO 64/52

1773, Ourense

Lista de los Canónigos y racioneros que han de recibir nieve el año 1773. ACO 64/19

17730118 , Ourense

Recibo de José Valdivia de 1474 rls por el abasto de la nieve del año 1772, al Cabildo de Ourense.

ACO 64/25

177306 18, Ourense

Recibo de 130 rls de vellón de los derechos del consumo de nieve del Cabildo de Ourense del año 1773.

ACO 64/53

17731213 , Ourense.

Recibo de José Valdivia de 1000 rls a cuenta del abasto de la nieve del año 1774, al Cabildo de Ourense.

ACO 64/15

"CUADERNOS DE ESTUDIOS GALLEGOS", Tomo XLVI, Fascículo 111, Santiago 1999. 
17731213 , Ourense.

Recibo de José Valdivia de 350 rls a cuenta del abasto de la nieve del año 1773, al Cabildo de Ourense.

ACO 64/16

1774, Ourense

Lista de los Canónigos y racioneros que han de recibir nieve el año 1774. ACO 64/20

177401 19, Ourense

Recibo de 130 rls de vellón de los derechos del consumo de nieve del Cabildo de Ourense del año 1774.

ACO 64/54

177407 10, Ourense

Recibo de José Valdivia de 1317 rls por el abasto de la nieve del año 1774 , al Cabildo de Ourense.

ACO 64/24

177501 28, Ourense

Recibo de 130 rls de vellón de los derechos del consumo de nieve del Cabildo de Ourense del año 1775.

ACO 64/55

1776, Ourense

Lista de los Canónigos y racioneros que han de recibir nieve el año 1776.

ACO 64/21

1776, Ourense

Recibo del carpintero Antonio de Prado de 1040 rls y 8 mrs vellón por la composición del Pozo de la Nieve.

ACO 64/37

177602 12, Ourense

Recibo de José Valdivia de 1530 rls por el abasto de la nieve del año 1776, al Cabildo de Ourense.

ACO 64/13

"CUADERNOS DE ESTUDIOS GALLEGOS", Tomo XLVI, Fascículo 111, Santiago 1999. 
177602 12, Ourense

Recibo de José Valdivia de 1000 rls a cuenta del abasto de la nieve del año 1777, al Cabildo de Ourense.

ACO 64/14

177604 23, Ourense

Recibo de 130 rls de vellón de los derechos del consumo de nieve del Cabildo de Ourense del año 1776

ACO 64/56

177612 19, Ourense

Recibo de Antonio de Prado de 1040 rls y 8 mrs del arreglo del pozo de la nieve.

ACO 64/34.

1777, Ourense

Lista de los Canónigos y racioneros que han de recibir nieve el año 1777. ACO 64/22

177701 07, Ourense

Recibo de Francisco Ferreiro de 1068 rls vellón por la composición del Pozo de la Nieve.

ACO 64/08

177701 23, Ourense

Recibo de 130 rls de vellón de los derechos del consumo de nieve del Cabildo de Ourense del año 1777

ACO 64/57

177712 29, Ourense

Recibo de José Valdivia de 1171 rls por el abasto de la nieve del año 1776, al Cabildo de Ourense.

ACO 64/12

177712 09, Ourense

Recibo de 130 rls de vellón de los derechos del consumo de nieve del Cabildo de Ourense del año 1778

ACO 64/58

"CUADERNOS DE ESTUDIOS GALLEGOS", Tomo XLVI, Fascículo 111, Santiago 1999. 
1778, Ourense

Lista de los Canónigos y racioneros que han de recibir nieve el año 1778. ACO 64/23

1778, Ourense

Recibo del carpintero Antonio de Prado de 1161 rls vellón por la composición del Pozo de la Nieve.

ACO 64/38

1778, Ourense

Razón de las «alhajas» pesar pesar y beneficiar la nieve que están en poder de Diego Vázquez, obligado del abasto de nieve al Cabildo de Ourense.

ACO 64/72

177801 05, Ourense

Contrato y obligación del abasto de la nieve al cabildo de Ourense con Diego Vázquez, vecino de Ourense para el año 1778.

ACO 64/69

177809 26, Ourense

Recibo de Juan Antonio Cid, capellán de coro de 900 rls por el abasto de la nieve del año 1778, al Cabildo de Ourense.

ACO 64/73

17781210 , Ourense

Recibo de 130 rls de vellón de los derechos del consumo de nieve del Cabildo de Ourense del año 1779

ACO 64/60

$1778-1785$, Ourense

Resumen del consumo y abasto de nieve estos años

ACO 64/36

1779, Ourense

Lista de los Canónigos y racioneros que gastaron nieve el año 1779.

ACO 64/30

"CUADERNOS DE ESTUDIOS GALLEGOS", Tomo XLVI, Fascículo 111, Santiago 1999. 
17790108 , Ourense

Contrato y obligación del abasto de la nieve al cabildo de Ourense con Juan Rubiano, maestro de obra prima para el año 1779.

ACO 64/76

\section{23, Ourense}

Contrato y obligación del abasto de la nieve al cabildo de Ourense con Juan Rubiano, maestro de obra prima por seis años: 1780-1785

ACO 64/75

178003 31, Ourense

Recibo de Antonio de Prado de 73 rls vellón por la composición del Pozo de la Nieve. ACO 64/07

17801214 , Ourense

Recibo de 130 rls de vellón de los derechos del consumo de nieve del Cabildo de Ourense del año 1780

ACO 64/61

1781, Ourense

Lista de los Canónigos y racioneros que gastaron nieve el año 1781.

ACO 64/29

\section{7 , Ourense}

Recibo de 130 rls de vellón de los derechos del consumo de nieve del Cabildo de Ourense del año 1781

ACO 64/62

1782, Ourense

Lista de los Canónigos y racioneros que gastaron nieve el año 1782.

ACO 64/06

178202 28, Ourense

Recibo de 130 rls de vellón de los derechos del consumo de nieve del Cabildo de Ourense del año 1782

ACO 64/63 
178303 20, Ourense

Recibo de 130 rls de vellón de los derechos del consumo de nieve del Cabildo de Ourense.

ACO 64/43

178403 31, Ourense

Recibo de 130 rls de vellón de los derechos del consumo de nieve del Cabildo de Ourense del año 1781.

ACO 64/62

1782, Ourense

Lista de los Canónigos y racioneros que gastaron nieve el año 1782.

ACO 64/06

178202 28, Ourense

Recibo de 130 rls de vellón de los derechos del consumo de nieve del Cabildo de Ourense del año 1782

ACO 0064/63

178303 20, Ourense

Recibo de 130 rls de vellón de los derechos del consumo de nieve del Cabildo de Ourense.

ACO 0064/43

178403 31, Ourense

Recibo de 130 rls de vellón de los derechos del consumo de nieve del Cabildo de Ourense.

ACO 64/05

178405 06, Pardeconde

Recibo de Marcos Fernández de Villarino de 40 rls vellón por el retejo del Pozo de la Nieve, del cabildo de Ourense.

ACO 64/09

178504 05, Ourense

Recibo de 130 rls de vellón de los derechos del consumo de nieve del Cabildo de Ourense del año 1785

ACO 64/64

"CUADERNOS DE ESTUDIOS GALLEGOS", Tomo XLVI, Fascículo 111, Santiago 1999. 
1785 06, Ourense

Anotación de las cargas y libras de nieve que se van entregando a capitulares del Cabildo de Ourense.

ACO 64/39

178506 30. Ourense

Carta de Francisco Ferreiro a Don Manuel Godoy sobre asuntos relacionados con el abasto de la nieve.

ACO 64/74

178506 20. Ourense

Testimonio sobre la provisión de la nieve al público, dirigida por el Ayuntamiento al Cabildo.

ACO 64/77

\section{2 , Ourense}

Instancia de Juan Rubiano, vecino del coto de Seixalbo y encargado del abasto de la nieve, al Cabildo, pidiendo le exima de tal obligación por el perjuicio económico que le causa.

ACO 64/79

17850623 , Ourense

Instancia de Francisco Gómez, sargento del Regimiento Provincial de Ourense solicita el encargado del abasto de la nieve, al Cabildo, por el cese de Juan Rubiano

ACO 64/80

178506 23, Ourense

Carta del Ayuntamiento al Cabildo sobre la provisión de la nieve con el deseo de limar las diferencias entre ambas comunidades.

ACO 64/81

178506 23. Ourense

Informe y acuerdo municipal en la disputa con el Cabildo sobre la provisión de la nieve.

ACO 64/82

"CUADERNOS DE ESTUDIOS GALLEGOS", Tomo XLVI, Fascículo 111, Santiago 1999. 
178506 27, Ourense

Carta del Cabildo al Ayuntamiento en relación con el abasto de la nieve, con el fin de solucionar los conflictos surgidos.

ACO 64/83

\section{8 , Ourense}

Carta de Francisco Gómez, sargento del Regimiento Provincial de Ourense al cabildo sobre su pretensión de encargarse del abasto de la nieve, al Cabildo, por el cese de Juan Rubiano.

ACO 64/84

178506 25, Ourense

Carta de Francisco Ferreiro a Don Manuel Godoy sobre asuntos relacionados con el abasto de la nieve.

ACO 64/86

178506 Ourense

Carta de Francisco Ferreiro a Don Manuel Godoy sobre asuntos relacionados con el pozo de la nieve y recibo de gastos.

ACO 64/87

\section{01, Ourense}

Contrato del abasto de la nieve al cabildo de Ourense con Francisco Gómez, sargento de milicias del Regimiento provincial de Ourense por tres años. ACO 64/85

178603 22, Ourense

Solicitud del Cabildo de Ourense, dirigida al Director de Rentas Provinciales, Manuel de la Lastra, para hacer el acopio de la nieve en el pozo de Cabeza de Meda, para el año 1786 previo pago de los 130 rls de vellón de los derechos acostumbrados.

ACO 64/42

178610 13, Pardeconde

Carta de Francisco Ferreiro a Don Felipe Blanco sobre asuntos relacionados con el pozo de la nieve.

ACO 64/88

"CUADERNOS DE ESTUDIOS GALLEGOS", Tomo XLVI, Fascículo 111, Santiago 1999. 
178904 06, Ourense

Contrato y obligación del abasto de la nieve al cabildo de Ourense con Juan Rubiano, maestro de obra prima para el año 1789

ACO 64/66

178907 09, Ourense

Recibo de 130 rls de vellón de los derechos del consumo de nieve del Cabildo de Ourense del año 1789

ACO 64/65

18071213 , Ourense

Contrato del abasto de la nieve al cabildo de Ourense con Antonio Garrido, natural de Pontevedra. (Traslado)

ACO 64/04

182104 11, Rocas

Carta de Fray Bernardo Rodríguez, cura de San Pedro de Rocas al Secretario del Cabildo dándole cuenta del estado del pozo de la nieve.

ACO 64/01

"CUADERNOS DE ESTUDIOS GALLEGOS", Tomo XLVI, Fascículo 111, Santiago 1999. 